Доржиева Ирина Цыдыпжаповна

кандидат социологических наук,

доцент кафедры политологии и социологии

Бурятского государственного университета

Мисайлова Виктория Валерьевна

выпускница кафедры политологии и социологии Бурятского государственного университета

\section{ФАКТОРЫ \\ ПОТРЕБИТЕЛЬСКОГО ПОВЕДЕНИЯ СТУДЕНЧЕСКОЙ МОЛОДЕЖИ: СОЦИОЛОГИЧЕСКИЙ АНАЛИЗ}

\section{Dorzhieva Irina Tsydypzhapovna}

PhD in Social Science, Assistant Professor, Political Science and Sociology Department, Buryat State University

Misaylova Viktoriya Valeryevna

Graduate student, Political Science and Sociology Department, Buryat State University

\section{FACTORS OF CONSUMER BEHAVIOR OF THE STUDENT YOUTH: A SOCIOLOGICAL ANALYSIS}

В статье рассматривается потребительское поведение студенческой молодежи, анализируются факторы, влияющие на него. На основе результатов социологического исследования выявлено воздействие на потребление в студенческой среде таких факторов, как уровень доходов, цена, качество товаров, реклама, мода и др.

Ключевые слова:

потребление, потребительское поведение, студенческая молодежь, уровень доходов, факторы потребительского поведения.
Keywords: consumption, consumer behavior, student youth, income level, factors of consumer behavior.

Проблема потребительского поведения все больше привлекает внимание представителей разных наук. Изначально анализ потребления строился сугубо в рамках экономического подхода, связанного с исследованием структуры спроса населения на товары и услуги, доходов и расходов групп населения и др. Основы для социологического изучения потребительского поведения были заложены в работах М. Вебера, Т. Веблена, Г. Зиммеля, В. Зомбарта, К. Маркса и др.

Потребление в социологии рассматривается как социальный и социально-психологический феномен, сфера социальных отношений, формирования социальных норм и ценностей. В процессе потребления человек не только удовлетворяет потребности, но и выражает свой социальный статус. Особенно это касается «демонстративного поведения», связанного с потреблением недоступных для большинства рядовых потребителей благ, которые определяют высокое социальное положение их владельцев [1]. «Функции товаров не сводятся к использованию их полезных свойств, они являются также важным средством социальной дифференциации в обществе» [2, с. 12].

Потребление является активным процессом по отношению не только к благам, но в первую очередь - к коллективу, социальной группе, обществу. Потребление носит совместный, общественный характер, поскольку индивид в той или иной мере ориентирован на других людей [3].

На потребительское поведение влияют изменения в социальной структуре, системе ценностей, стиль жизни и др. [4]. Среди множества фракторов, детерминирующих потребление, можно выделить следующие их группы:

1) экономические фракторы - уровень доходов, инфляции;

2) социальные фракторы - социальное положение, социальная роль;

3) культурные факторы - культурные ценности, нормы потребления, принятые в той или иной культуре;

4) психологические - личные потребности, мотивы, установки, привычки, характер людей, эмоциональное состояние;

5) личностные - пол, возраст, национальность, образование и др.

Социально-экономические процессы в современном российском обществе влияют на характер потребительского поведения разных социальных групп. Особой группой потребителей является студенческая молодежь. С одной стороны, студенты ориентируются на инновации, склонны к новаторству и экспериментам, обладают большим потребительским потенциалом. 
С другой - большинство из них не имеют собственных доходов и во многом зависят от материальной поддержки родителей. Студенты - социальная группа, неоднородная по своему составу. Выступая потребителями товаров и услуг, они демонстрируют разнообразные стили потребления, определяющие различные типы потребителей.

В статье представлены результаты социологического исследования потребительского поведения студентов Бурятского государственного университета, проведенного в 2016 г. В качестве основного метода сбора данных применялся анкетный опрос с использованием специально разработанной анкеты, в ходе которого было опрошено 150 студентов. Респонденты отобраны методом квотной выборки с учетом пола, возраста, места жительства до обучения в университете.

Одним из основных факторов потребительского поведения выступает уровень доходов потребителей, оказывающий прямое влияние на спрос. Студенты, главным видом деятельности которых является учеба, не вовлечены в активную трудовую деятельность. Ведущим источником доходов у большинства студентов служит помощь родителей. Так, 83 \% опрошенных прибегают к их материальной помощи, $27 \%$ назвали помощь родителей базовым и даже единственным источником дохода. При этом 55 \% респондентов получают стипендию, 14 \% из них считают ее ключевым фринансовым источником. Равное количество молодых людей отметили временные подработки и социальные выплаты - по 20 \%. Однако социальные выплаты представляют собой основной источник дохода лишь для 1 \% студентов, а временные подработки не выступают для них в этом качестве.

Заработную плату как источник доходов указали 12 \% респондентов. Как правило, трудовая занятость не связана с профилем получаемого образования, студенты в связи с учебой работают неполный рабочий день и, соответственно, не имеют высоких зарплат. Только 2 \% опрошенных отметили, что заработная плата является основным источником их доходов.

Уровень доходов определяет материальное благосостояние людей. Анализ материального положения студентов основывался на субъективной оценке опрошенными своего благосостояния. Половина респондентов (51\%) отметили, что денег хватает на продукты питания и одежду, а покупка достаточно дорогих вещей проблематична. 38 \% опрошенных указали, что средств хватает лишь на продукты, а приобретение одежды вызывает затруднения. 8 \% студентов не испытывают материальных трудностей и могут позволить себе дорогостоящие вещи. Крайне нестабильное материальное положение имеют 3 \% студентов, они ответили, что денег им не хватает даже на еду.

По результатам опроса выявлено, что основное место в структуре расходов студентов, живущих отдельно от родителей, занимают продукты питания, это отметили $86 \%$ респондентов. Второе место в равной степени занимают одежда и общественный транспорт (45 \%). Почти половина опрошенных (48 \%) на третье место поставили общественное питание.

Среди студентов, проживающих с родителями, 39 \% на первое место поместили расходы на одежду. У 46 \% респондентов второе место в структуре затрат занимает общественный транспорт, на третьем месте находится общественное питание - 21 \% опрошенных отметили эту статью расходов.

Основными фракторами при выборе продуктов питания для студентов являются цена (57 \%) и качество (43\%). Однако мужчины в меньшей мере обращают внимание на качество товара $(37,5 \%)$, чем женщины $(48,5 \%)$.

Цена как определяющий фактор при выборе продовольственных товаров наиболее важна для студентов, имеющих низкое материальное положение. Все обучающиеся, у которых доходов не хватает даже на продукты питания, отметили их стоимость как самый главный критерий. 78,4 \% респондентов, у которых доходов хватает на продукты, но покупка одежды вызывает трудности, также обращают внимание на цену. Только 37,3 \% опрошенных, чьи доходы позволяют без затруднений покупать еду и одежду, отметили стоимость как первостепенный фрактор, основная часть этих студентов ориентируются на качество продуктов.

Значимым фактором при выборе одежды также является цена товара, на нее ориентируются более половины респондентов (56 \%). Комфорт ценят $54 \%$ опрошенных, на качество вещей обращают внимание 49 \%. Треть студентов выбирают одежду, которая им наиболее подходит. Моду как самый важный фрактор при выборе одежды отметили всего $11 \%$ молодых людей, а престижность марки одежды - $8 \%$.

В то же время при рассмотрении влияния моды на потребительское поведение молодежи выявлено, что для большинства молодых людей при покупке товара важно его соответствие модным тенденциям. Только 23 \% респондентов не обращают внимания на это при выборе вещей. Среди них в основном сельские студенты и мужчины.

Согласно результатам опроса наиболее важный фрактор при выборе товаров длительного пользования - это качество, его отметили 74 \% респондентов. На данный критерий обращают 
внимание 100 \% студентов, имеющих высокий уровень доходов, и 66 \% молодых людей с низким уровнем доходов. На втором месте по значимости находится цена (35 \%), а на третьем - производитель товара (25 \%). Торговая марка играет максимально значимую роль для 15 \% опрошенных, 7 \% из них ответили, что для них важнее всего новизна модели, а 4 \% - престижность. По 1 \% опрошенных ценят внешний вид и удобство товаров длительного пользования.

Один из маркетинговых ходов, применяемый для поднятия спроса на товар, - реклама. Однако результаты опроса показали, что большинство студентов при выборе товара не ориентируются на его рекламу (79 \%), только 16 \% респондентов выбрали бы наиболее разрекламированный товар, а 5 \% опрошенных сообщили, что скорее предпочтут товар, который они не часто видят в рекламе или не видят совсем.

Социальные связи также влияют на выбор товаров и услуг. 30 \% студентов всегда прислушиваются к советам родственников, друзей и знакомых, 61 \% иногда ориентируются на мнение близких людей и только 9 \% руководствуются личным мнением. В основном мнение окружающих считают важным студенты женского пола.

Таким образом, в силу ограниченных материальных средств студенты в меньшей степени используют товары для демонстрации своего статуса. «Показное» поведение наиболее характерно для респондентов с высоким уровнем доходов, основную долю которых составляет материальная поддержка родителей. Такие молодые люди в большей степени ориентируются на модные тенденции, новинки, брендовые вещи.

Для большинства опрошенных главными факторами при совершении покупки выступают цена и качество. Ориентация на качество чаще всего проявляется при приобретении товаров длительного пользования. Цена товара наиболее значима для студентов с низким уровнем доходов и в основном служит определяющим фактором при покупке продуктов питания.

\section{Ссылки:}

1. Веблен Т. Теория праздного класса. М., 1984.

2. Радаев В.В. Социология потребления: основные подходы // Социологические исследования. 2005. № 1. С. 5-18.

3. Кучеренко Е.А. Интегральная модель потребления в современном обществе // Теория и практика общественного развития. 2014. № 3. С. 67-70.

4. Glock Ch.Y., Nicosia F.M. Uses of sociology in studying «consumption» behavior [Электронный ресурс] // Journal of Marketing. 1964. Vol. 28. P. 51-54. URL: https://archive.ama.org/archive/ResourceLibrary/JournalofMarketing/documents/6740885.pdf (дата обращения: 18.04.2017).

\section{References}

Glock, ChY \& Nicosia, FM 1964, 'Uses of sociology in studying "consumption” behavior', Journal of Marketing, vol. 28, pp. 51-54, viewed 18 April 2017, <https://archive.ama.org/archive/ResourceLibrary/JournalofMarketing/documents/6740885. pdf>, https://doi.org/10.2307/1249158

Kucherenko, EA 2014, 'Integrated model of consumption in a modern society', Teoriya i praktika obshchestvennogo razvitiya, no. 3, pp. 67-70, (in Russian). sian).

Radaev, VV 2005, 'Sociology of consumption: basic approaches', Sotsiologicheskiye issledovaniya, no. 1, pp. 5-18, (in Rus-

Veblen, T 1984, Theory of the leisure class, Moscow, (in Russian). 